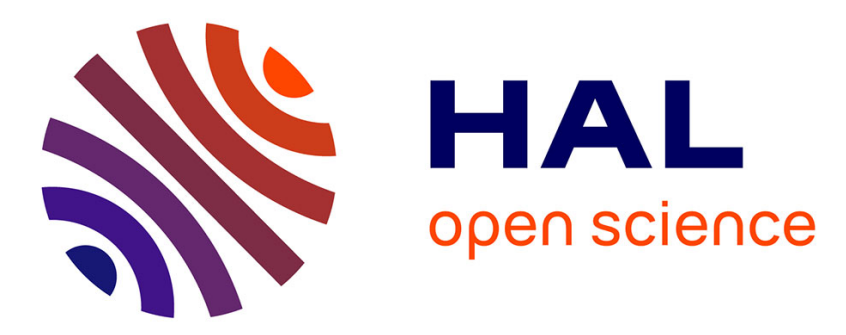

\title{
Reducing consumption of electricity: A field experiment in Monaco with boosts and goal setting
}

\author{
Nathalie Lazaric, Mira Toumi
}

\section{To cite this version:}

Nathalie Lazaric, Mira Toumi. Reducing consumption of electricity: A field experiment in Monaco with boosts and goal setting. Ecological Economics, 2022, 191, pp.107231. 10.1016/j.ecolecon.2021.107231 . halshs-03402212

\section{HAL Id: halshs-03402212 \\ https://shs.hal.science/halshs-03402212}

Submitted on 25 Oct 2021

HAL is a multi-disciplinary open access archive for the deposit and dissemination of scientific research documents, whether they are published or not. The documents may come from teaching and research institutions in France or abroad, or from public or private research centers.
L'archive ouverte pluridisciplinaire HAL, est destinée au dépôt et à la diffusion de documents scientifiques de niveau recherche, publiés ou non, émanant des établissements d'enseignement et de recherche français ou étrangers, des laboratoires publics ou privés. 


\title{
Reducing consumption of electricity: a field experiment in Monaco with \\ boosts and goal setting
}

\author{
Nathalie LAZARIC*, and Mira TOUMI**1
}

\begin{abstract}
We investigate the complementarity among different treatments which involved "boosts" (provision of information) and "goals" (ambitious or modest goals) by means of a field experiment conducted in the Principality of Monaco between December 2018 and May 2019. We collected data from 77 households in four groups: ambitious electricity reduction goal combined with information (Treatment 1), modest electricity reduction goal combined with information (Treatment 2), only information (Treatment 3), and a control group (CG). Treatments 1 and 2 increased the chances of reduced electricity consumption. We show that a modest, more realistic electricity saving goal when combined with a "boost" generates better electricity conservation performance (T2). We explore the link between behavioral strategies and the household's concern for the environment in the context of the new ecological paradigm (NEP). Our results show that treatments $\mathrm{T} 1$ and $\mathrm{T} 2$ are efficient for reducing electricity consumption only in households with high levels of environmental concern; those whose level of concern about the environment is low will not respond to any of the behavioral interventions. We provide some recommendations for the implementation of behavioral tools and "boosts".
\end{abstract}

Keywords: Boost, nudges, goal setting, electricity consumption, field experiment, environmental profile.

\footnotetext{
$1 *$ Groupe de Recherche en Economie Droit et Gestion, Université Côte d'Azur, 250 Rue Albert Einstein, 06560 Valbonne, France, nathalie.lazaric@gredeg.cnrs.fr

** Corresponding author: Groupe de Recherche en Economie Droit et Gestion, Université Côte d'Azur, 250 Rue Albert Einstein, 06560 Valbonne, France, mira.toumi@gredeg.cnrs.fr
} 


\section{Introduction}

Behavioral tools have attracted the attention of policy makers by providing concrete mechanisms and allowing actions in a range of fields: health, waste, energy preservation, nutrition among others (Hertwig and Ryall, 2020). The myriad examples around the world of use of nudges show their inherent attractiveness. It has been shown that certain behavioral tools such as nudges, boosts, and goals can promote green behaviors. Among these behavioral tools, boosts seem to have good potential by empowering individuals to rid themselves of biased judgments. For policy makers, agency is an important issue (i.e. how to influence changes at the individual level, in which context, and for what reasons). These ethical issues should not be neglected in deciding about appropriate tools. The adoption of greener behaviors is hampered by material, technological, financial, psychological and other dimensions. These biases mean that traditional approaches such as awareness campaigns and technological innovations proposed by standard economists may fail to generate lasting change. Behavioral economics may provide robust tools to help to reduce energy use, conserve water, and tackle nutrition, and health issues to accelerate the ecological transition; however, their implementation requires certain conditions.

Indeed, changing individual behavior towards reducing consumption of electricity takes much time and effort and is affected by problems such as potential inertia, individual agency, and motivation. These problems are linked to an overemphasis on energy efficient equipment policies rather than behavioral actions which improve individual level abilities (Maréchal and Holzemer, 2015; Buckley, 2020). Additionally, electricity is an invisible commodity which contributes to lack of awareness about its daily consumption (Hargreaves et al., 2013). European households are poorly informed about their electricity use and may lack knowledge about how to act on this issue (Belaïd and Joumni, 2020; Buckley, 2020).

Among the non-monetary tools that have been applied in the context of electricity consumption, nudges have become increasingly popular for correcting certain behavioral cognitive biases (Buckley, 2020; Schubert, 2017). In a recent meta-analysis of monetary and non-monetary interventions for households, Buckley (2020) shows that they can result in an overall reduction in electrical energy consumption of between $1.87 \%$ and $3.91 \%$. When she compared differences among behavioral tools, Buckley found that monetary tools did not have a significant effect whereas non-monetary tools such as "information on households own consumption delivered 
via paper bills, online or in real-time and personalized advice are found to be most effective at lowering residential electricity consumption" (Buckley, 2020: 12).

Nudges which have been identified as promising for reducing electricity consumption (Charlier et al., 2020) suffer from several ethical problems (Schubert, 2017; Bradt, 2019; Hertwig and Ryall, 2020). They can alter citizens' behaviors by harnessing their cognitive biases but may not generate robust and durable behavioral changes. They are also highly context dependent (Schubert, 2017; Allcott and Rogers, 2014).

Boosts are seen as different from nudges (Schubert, 2017) and "self-nudges" (Reijula and Hertwig, 2020) and are attracting the attention of policy makers and practitioners (DellaValle and Sareen, 2020). Boosts allow citizens to improve their skills (Herwig, 2017). While proponents of nudges consider that human beings are prisoners of their automatic systems of cognition (Kahneman, 2011), proponents of boosts assume that individual competences can be enhanced and that individuals can overcome their biases through training (Hertwig and Ryall, 2020; Bradt, 2019). Thus, although boosts have attracted less attention than nudges, they represent an interesting line of enquiry in the context of behavioral tools to improve households' knowledge about electricity consumption.

Another behavioral tool which has been used in the context of reducing electricity consumption is goal setting. Andor and Fels (2018) consider that a goal can become a concrete point of reference whose accomplishment will increase extrinsic forms of motivation. Goals combined with advice have received little research attention and are "a promising avenue for further research" (Anders and Fels, 2018: 186).

Given the limitations of nudges (Rebonato, 2012) and the unexplored potential of boosts combined or not with goals, we decided to investigate the relevance of these latter in the case of Monaco, a sovereign city-state located on the French Riviera in Western Europe. Monaco is interesting for at least two reasons. First, local government is keen to achieve an energy transition, and second, there are no empirical studies on this geographical area. In 2018 we implemented a field experiment designed to tackle the issue of reducing electricity consumption and measuring the effects on citizens' electricity consumption of boosts and goals.

We collected data from 77 households in four groups: ambitious electricity reduction goal combined with boosts (T1), modest electricity reduction goal combined with boosts (T2), only 
boosts (T3), and a control group with no goals and no boosts (CG). Our empirical findings show that the T1 and T2 groups reduced their electricity use which suggests that goals - especially realistic goals - combined with a boost produce better outcomes in terms of behavioral change.

The paper is organized as follows. Section 2 reviews the literature on behavioral tools related to electricity consumption. Section 3 describes the design of the experiment and the protocol, and section 4 presents the data analysis. Section 5 examines the sample and the data, and section 6 presents the results. Section 7 discusses our findings and some limitations of our study and whether it could be replicated in other contexts. Section 8 concludes the paper and provides some recommendations for policy.

\section{Behavioral tools and electricity consumption: a short review}

Policy makers are often inspired by behavioral science in their policy design and policy adaptations to different contexts (Schleyer, 2017; DellaValle and Sareen, 2020). According to Dolan et al. (2012), the most effective interventions for persuading individuals to adopt green behaviors are those which aim to change contexts and mindsets which suggests that nudges, goals, and boosts might be effective behavioral interventions. However, ethical assumptions and sources of inspiration for these behavioral tools differ. These divergences are explained and discussed below.

\subsection{Nudges and boosts -are they similar or different?}

According to Grüne-Yanoff and Hertwig (2016), the provision of information can affect behavioral interventions depending on the stage at which and the form in which the information is provided ${ }^{2}$. Nudges intervene by changing the context and architecture of the decision-making process and consider individuals' cognitive biases and exploit them in the absence of any individual motivation (Thaler and Sunstein, 2008). Nudges are defined as "any aspect of the choice architecture that alters people's behavior in a predictable way without forbidding any options or significantly changing their economic incentives. To count as a mere nudge, the intervention must be easy and cheap to avoid" (Thaler and Sustein, 2008: 6). In an energy

\footnotetext{
${ }^{2}$ The authors propose a set of policy intervention categories based on an analogy with mechanisms and decision making. These categories include existence of i) a decision making environment which includes an amount of available information and the decision context, ii) a set of search and selection rules which provide a set of information which the decision maker can use and choose among, and iii) a set of available options with different properties.
} 
context, nudges have proven promising in terms of promoting green behaviors (Allcott, 2014; Charlier et al., 2020). Moreover, compared to traditional monetary tools such as taxes, nudges are relatively effective depending on the household's environmental sensitivity profile (My and Ouvrard, 2019).

Boosts differ in that they aim not to influence behavior but to create the conditions for learning. They do not change the choice architecture, but they foster individual competence to overcome rather than exploit cognitive biases (Schubert, 2017; Hertwig, 2017): "The common denominator behind boost policies is the goal of empowering people by expanding (boosting) their competences and thus helping them to reach their objectives (without making undue assumptions about what those objectives are)" (Grüne-Yanoff and Hertwig, 2016: 156). In other words, while nudges exploit the individual's unconscious and push them towards the "right" decision, boosts foster people's competence to make a conscious choice and exercise agency. Boosts aim to train individuals through the provision of relevant information, and thus, to empower them to become their own choice architects (Grüne-Yanoff and Hertwig, 2016; Hertwig and Grüne-Yanoff, 2017).

Bradt (2019) describes nudges and boosts as different in terms of their sources of inspiration and their implementation. Nudges consider prior heuristics at the individual level and assume cognitive bias as a matter of fact and act to try to overcome them; boosts are aimed at improving existing skill levels and changing certain individual heuristics and cognitive biases. Thus, boosts enter the cognitive black box to improve the level of existing skills and target the repertoire of individual heuristics directly and not just the environment.

More precisely, in a nudge view, heuristics are considered stable. This is based on Kahneman who distinguishes between system 1 "which operates automatically and quickly, with little or no effort and no sense of voluntary control" (Kahneman, 2011:20) and is "not really educable" (Kahneman, 2011: 41), and system 2 which is slow, deliberate, conscious, controlled by the mental process and rational thinking. In contrast, the boost view inspired by the Fast and Frugal Heuristics program (Gigerenzer et al., 1999) considers that individuals are equipped with various sets of competences and have the option to choose among heuristics and select the most appropriate for his or her goals (Grüne-Yanoff et al., 2018: 249). Boosts and nudges have different ontological visions. In a nudge view, someone indicates the "proper" way to act in a particular context, while boosts deliver the tools required to act to solve the issue. 
Boosts also differ from feedback and simple provision of information. Some feedback enables learning. It has been shown that learning-by-observing is based on feedback from use of household appliances (Kendel et al., 2017) over a prolonged period (more than 6 months) which allows the information to be absorbed and used to improve individual skills. Boosts aim to enable learning through continuous provision of information. Thus, the difference between feedback and boosts is based on the difference between information and knowledge. Feedback provides additional information and may enhance the conditions required for learning. Boosts increase individual learning and change individual heuristics but may require some investment to enable the learning. In addition, the content of the information provided by a boost is richer and more customized compared to the information contained in feedbacks.

\subsection{Boosts and nudges: which tool can be chosen and implemented?}

Nudges act to change behavior in the short term (Charlier et al., 2020) whereas boosts require some investment in training and need a long-term perspective to observe concrete results. Boosts give customized and recurrent advice which change individual heuristics and provide the ability to learn. A required condition for using boosts as a behavioral tool, is motivated participants. If motivation is low and the situation is very complex, for instance in some cases of risks in the insurance sector, nudges may appear more useful and easier to implement. As Bradt (2019) states, in principle, there are no good or bad behavioral tools but rather instruments that are more appropriate in some situations and some contexts. For instance, a policy maker should start with nudges and then implement boosts. Once boosts are implemented nudges are no longer either necessary or useful. Policy makers must choose between what can be done and what can be achieved based on the initial local conditions.

The choice among behavioral tools should be driven also by welfare, education concerns, and the policy framework. It has been acknowledged that:

despite the widespread appeal of nudging, there are some limits. For instance, it is hard to imagine how without empowering people one could offer lasting and robust remedies to the problem bias, intentional; misinformation and micro-targeting present they face by today's media consumers [...] Equipping citizens to make judgment of information quality independently and competently is -despite the manipulation efforts- is indispensable to maintaining democratic forms of government. (Hertwig and Ryall, 2020: 1410) 
Issues of democratic participation and learning may be more responsive to boosts to tackle misinformation among citizens about climate change (see van der Linden et al., 2017, for a longer discussion). Boosts are part of the capabilities approach in the sense of Sen (1999) since they consider humans as "intrinsically capable of acquiring greater abilities as they access degrees of freedom to act" (Della Valle and Sareen, 2020: 101). Democratic participation in the ecological transition can mean that boosts may provide the tools to empower actors who can influence economic and social change. This debate goes beyond tools and should be driven by policy, the local context, and the available resources. Boosts are more effortful and complex to implement than nudges. Thus, policy maker should remember that people are prone to making errors and suffering from cognitive biases. Devoting attention to learning is a prerequisite for promoting collective action to achieve an ecological transition and to allow citizens to participate in this shift. This issue is discussed in Banerjee and Duflo (2009) who argue that field experiments need to be co-designed by policy makers and researchers. Also, the results of field experiments must be assessed before considering replication or generalization.

\subsection{Setting appropriate goals}

Interventions that involve goals lead to efforts which persist over time (Locke and Latham, 2006). Goal setting promotes additional effort and commitment to achieve the goal (McCalley and Midden, 2002).

In an energy use context, goals whether imposed by a third party or chosen by the individual can have a positive effect on energy use (Dolan et al., 2010). However, the ambitiousness of the goal matters. Abrahamse et al. (2005) and Wood and Newborough (2007) show that more ambitious compared to modest goals lead to higher energy savings. However, a goal perceived as unrealistic reduces individual motivation. For example, Harding and Hsiaw (2014) show that goals need to be realistic: too modest goals require little effort for their achievement. However, if the goal is considered unrealistic, the individual will make no efforts to try to achieve it. Harding and Hsiaw (2014) studied a group of individuals residing in Northern Illinois in the United States where the citizens chose their energy consumption goals. A goal of reducing consumption by $15 \%$, achieved better results (11\% reduction) than very low or unrealistically high goals. In their frame, goals greater than $0 \%$ but less than $15 \%$ were considered "realistic" whereas 15\%-50\% goals were considered "over -optimistic" (Harding and Hsiaw, 2014). Who sets the goal is also important and Abrahamse et al. (2005: 266) argue that although the "goal 
can be set by households themselves or by some external entity ... research suggests that there is no difference in energy savings between the two".

Our methodological design involves a goal imposed by an external entity. This ensures a better balance among our diverse groups since volunteers are more likely to choose a realistic goal. Also, this allows investigation of the effect of a promising new behavioral tool a "boost" combined with a goal as discussed above, with possible more lasting behavior change rather than short-term behavior changes (Hertwig and Grüne-Yanoff, 2017). Following Buckley (2020), we combine goal setting with boosts, and observe the impact of boosts as explained in more detail below.

\section{Experimental design}

\subsection{Field experiment method and recruitment of participants}

The field experiment was conducted in the Principality of Monaco over the six-month period December 2018 to May 2019 (see figure 1). This is a unique setting. First, a large proportion of its population are financially well endowed and live in apartments in tower blocks that were built mostly in the 1970s. Second, average electricity consumption per inhabitant in Monaco tends to be below the average for its neighbor France. However, this is due mostly to Monaco's residents spending only part of the year in Monaco rather than because they are more careful about their energy consumption which makes comparison difficult. Third, 90\% of Monaco's electrical energy is supplied by France and includes a high percentage of renewable electricity ( $75 \%$ for Monaco compared to only $20 \%$ for the whole of France). This promotes more careful use of energy and more attention to the environment ${ }^{3}$. Fourth, its government is involved in a retrofitting program to reduce greenhouses gas emissions from buildings and ensure that all new buildings conform to environmental standards.

We conducted the field experiment with the support of the main local energy provider (SMEG) based on a clear division of tasks to build trust and provide transparency for volunteers about the scientific objectives of our protocol. A letter of invitation was sent out by the local provider

\footnotetext{
${ }^{3}$ The 2017 White Book on the Energy Transition in the Principality of Monaco describes the aim of reducing greenhouse gas emissions by $80 \%$ (compared to 1990 levels) by 2050, and achieving carbon neutrality in the long run.
} 
and the scientific team to 5,000 households ${ }^{4}$ across the Principality to ensure inclusion of a diverse range of buildings including social housing, and a range of citizens from employees to professionals to ensure a representative sample. Consultation with SMEG ensured that the sample included different types of dwellings with different heating systems (not just based on electricity) and dwellings that were not part of the current retrofitting program. Agreement to participate was by freepost surface mail response or by email. Eligibility was based on two criteria: access to the Internet, and not being involved in the insulation program running during the period of the experiment.

We received a total of 127 positive responses. The participants were asked to complete a questionnaire $^{5}$ at two fixed points in time: prior to the treatment, and six months after the experiment. The ex-ante questionnaire asked about the household's socio demographics, ecological concerns and commitment, electricity use, heating system, and curtailment behaviors. The ex-post questionnaire was aimed at capturing changes to household socio demographics, household composition, and energy use and obtain feedback on the experiment. The timeline is depicted in figure 1.

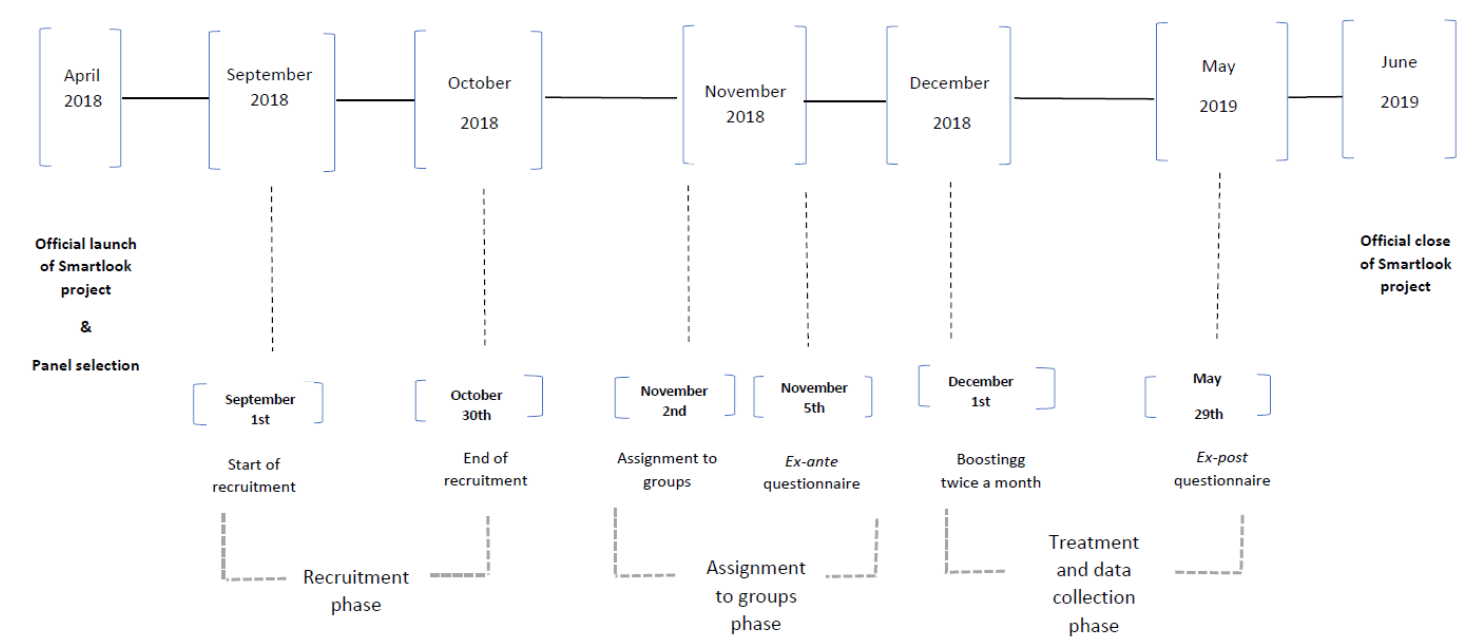

Figure 1: Timeline and main phases of the Smartlook field experiment

\subsection{Treatments and groups}

Conditional on replying to the ex-ante questionnaire, participants were randomly assigned to one of the experimental treatments or to the control group. Methodologically, the sampling

\footnotetext{
${ }^{4}$ The Principality of Monaco included 38,300 inhabitants in 2018 (source: Monaco en chiffres, IMSEE, 2019). The letter is provided in appendix 1-a; appendix 1-b describes the location in the Principality of Monaco.

${ }^{5}$ Available in French, English and Italian.
} 
strategy relied on households who volunteered to participate which is similar to other opt-in methods and is described by Harrison and List (2004) as a "framed field experiment". This indicates that volunteer-based experiments do not preclude random assignment of participants to different groups (see also Gandhi et al., 2016 and Karlin et al., 2015 on random assignment in electricity related field experiments).

Participants in the three treatment groups were informed that they would receive twice-monthly emails containing instructions with a reminder of their electricity use reduction goal (if assigned to a group with a goal), and a set of boosts ${ }^{6}$. The emails sent to the control group informed them only that they were part of an experiment aimed at gathering information on Monegasque households' energy transition. The households in the control group responded to both the exante and ex-post questionnaires but had no goals and did not receive boosts. However, to establish transparency and trust as recommended by Vassileva et al., (2013) and discussed in Kendel et al., (2017) all four groups were told that they would receive a summary of our empirical findings.

Despite declared willingness to participate in the experiment, the final sample included only 77 households that fulfilled the criteria of responding to the ex-ante questionnaire and being permanent inhabitants during the period of the field experiment. 89 of the original 127 volunteers completed the ex-ante questionnaire but this included 12 households not resident in Monaco throughout the period of the experiment.

Table 1: Sample allocation and treatments

\begin{tabular}{|c|c|c|c|c|c|c|c|}
\hline Treatments & Label & $\begin{array}{c}\text { Ex-ante } \\
\text { quest }\end{array}$ & Goal setting & Boosts & $\begin{array}{c}\text { Ex-post } \\
\text { quest }\end{array}$ & $\mathrm{N}$ & $\begin{array}{c}\text { Observation } \\
\text { Period }\end{array}$ \\
\hline $\mathrm{T} 1$ & Boost \& ambitious goal & + & + & + & + & 16 & 28 weeks \\
\hline T 2 & Boost \& modest goal & + & + & + & + & 17 & 28 weeks \\
\hline T 3 & Boost only & + & - & + & + & 21 & 28 weeks \\
\hline CG & Control group & + & - & - & + & 23 & 28 weeks \\
\hline Total & & & & & & 77 & 28 weeks \\
\hline
\end{tabular}

\footnotetext{
${ }^{6}$ Boosts were formulated by the project team building on ADEME (the French Environment and Energy Management Agency) statistics and information from other environmental associations. The information provided to participants consisted of an explanation of the problems related to electricity consumption and some practical advice about how to reduce it. The boosts were aimed at increasing participants' knowledge and skills. The boosts were in line with time of year (Christmas time, the beginning of spring). Boosts were sent by email and were aimed at increasing the volunteers' knowledge and learning (see appendices 2, 3-a and 3-b for details and examples).
} 
Table 1 presents the grouping of participants and the treatments:

- Treatment $1(n=16)$ : volunteers set an ambitious electricity consumption reduction goal compared to the previous six months usage $(25 \%)$ and received boosts on electricity saving.

- Treatment $2(\mathrm{n}=17)$ : volunteers set a modest (15\%) electricity consumption reduction goal compared to the previous six months usage, and a set of boosts.

- Treatment $3(n=21)$ : volunteers who received only boosts (advice) about how to reduce their electricity consumption.

- Control Group (=23): the control group of volunteers who received neither a goal nor boosts.

\section{Data analysis}

\subsection{Dependent variable: household consumption of electricity}

Quarterly data on electricity consumption in $\mathrm{kWh}$ were provided to each volunteer household by the local provider. These data allowed us to build our dependent variable i.e. average household electricity consumption per month in $\mathrm{kWh}$. We measured the dependent variable at two points in time: pre-treatment period ( 6 months), and intervention period ( 6 months $)^{7}$. This allowed us to estimate the change in household electricity consumption in the treatment groups linked to the treatment and/or variables such as environmental concern (explanatory variables).

\footnotetext{
${ }^{7}$ The collaboration with the SMEG gave us access to data on the electricity consumption of a sample of permanent residents over a 12 month period. To avoid the sample including temporary residents, SMEG identified households who were resident in the 6 months before the start of the experiment. To adjust and correct for potential effects of season, we included variables for weather and average consumption of electricity in Monaco. Average electricity consumption per treatment in $\mathrm{kWh}$ over the 6 months before and during the experiment including $95 \%$ confidence values is provided in appendices 4-a and 4-b. We observed that the consumption of the treatment groups differed statistically from that of the control group. We observed also that in June, July, and August (before the experimental intervention) average consumption did not differ statistically among T1, T3, and the CG. During the first 3 months of the experiment, December, January, and February we observed different average consumption; at the $95 \%$ confidence level average consumption was higher in the CG compared to the T1, T2, and $\mathrm{T} 3$ groups (see appendix 4-c).
} 
4.2. Explanatory variables: environmental concern, environmental commitment, curtailment behaviors, dwelling

Our explanatory variables include environmental values and commitment, participant's sociodemographic characteristics, dwelling type (i.e., owned or rented), and energy practices in line with Belaïd and Joumni (2020).

The presence of altruistic and/or biospheric values (see Stern and Dietz 1994) i.e., the weight given to outcomes affecting other individuals, and broader environmental concerns are considered among the principles guiding lifestyle (Schwartz 1992) and explain the likelihood of engaging in a range of environmentally relevant behaviors (Baum and Gross 2017). Most work on individual environmental values uses survey data and measures based on self-reported behavior, behavioral intentions, or other expressions of concern for the environment. We used Dunlap et al.'s (2000) NEP or New Ecological Paradigm scale which is used widely in psychology and shows high internal reliability and provides good results allowing control for and prediction of pro-environmental behavior (Davis et al., 2009).

We measure environmental commitment based on membership of an environmental association. Stern (2000: 409) defines environmental citizenship as including "petitioning on environmental issues and contributing to environmental organizations". It follows that environmental citizenship is captured by the activation of feelings of personal obligation to act and actions related to an association.

We include a set of virtuous behaviors related to energy practices i.e., curtailment behaviors affecting energy consumption (e.g., turning off the heating system when not in the house, not using the prewash program on the washing machine, etc. $)^{8}$ to measure energy behaviors (as discussed in the GEB or General Ecological Behavior scale). The GEB includes 40 questions (Kaiser 1998) about energy behavior. We selected five items related to energy behaviors from Kaiser and Biel (2000) to describe energy behaviors as explained by Kaiser et al. (2003) 9 .

\subsection{Difference-In-Differences method}

To estimate the causal relationships between the treatments and the levels of electricity consumption, we compare the performance of the treated and non-treated household groups

\footnotetext{
${ }^{8}$ For more detail see Nauges and Wheeler (2017).

${ }^{9}$ Appendix 5 provides details of items selected to define energy behavior.
} 
before and after the field experiment. The three treatment groups received three different treatments: (T1) ambitious goal setting and boost; (T2) modest goal setting and boost, and (T3) only boost. Following Angrist and Pischke (2008), we employ difference-in-differences (DID) estimations to control for household characteristics and we clustered standard errors to households. The DID method allows us to control for observed and unobserved time invariant characteristics and time-varying factors common to all groups which might be correlated to the treatments. Our counterfactual is the variation in the control group's electricity consumption i.e., the amount of electricity that would have been consumed without the treatment ${ }^{10}$.

To estimate the treatments effect, we rely on the following DID estimation equation (Eq. (1))

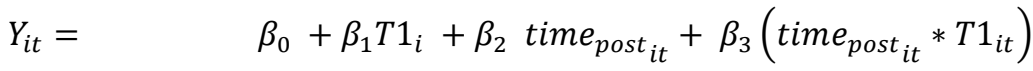

$$
\begin{aligned}
& +\beta_{4} T 2_{i}+\beta_{5}\left(\text { time }_{\text {post }_{i t}} * T 2_{i t}\right)+\beta_{6} T 3_{i}+\beta_{7}\left(\text { time }_{\text {post }}{ }_{i t} * T 3_{i t}\right) \\
& +(\text { individual s characteristics })^{\prime} \beta_{8}+(\text { dwelling characteristics })^{\prime} \beta_{9} \\
& +\beta_{10} \text { weather temperature }+\varepsilon_{i t}
\end{aligned}
$$

where $i$ and $t$ refer to the household $i$ treated with treatment $T$. We observe households in two periods, before the treatment $(t=0)$ and after the treatment $(t=1)$.

$Y_{i t}$ the dependent variable of interest is average monthly electricity consumption by household $i$ at time $t . \beta_{0}$ is the constant term and is the electricity consumption of the control group in the reference period June to November 2018.

The dummies ( $T 1_{i} T 2_{i} T 3_{i}$ ) equal 1 if the household received the corresponding treatment (treatment 1 , treatment 2 , or treatment 3 ) and zero otherwise. Therefore $\beta_{1}\left(\beta_{4}\right.$ and $\beta_{6}$ ) capture the differences among the households included in the T1 (T2 and T3 ) group and the households in the control group before the treatments.

time $_{\text {post }_{i t}}$ is a time dummy which takes the value 0 before the treatment and 1 after treatment is introduced. Therefore, $\beta_{2}$ captures the change in households' electricity consumption in the absence of treatments.

\footnotetext{
${ }^{10}$ We checked the parallel trend assumption i.e. that before the experiment the treated and non-treated groups were characterized by parallel trends; in our case, this means that the control group's average electricity consumption was similar to the consumption in the treatment groups (T1, T2, T3) before the treatment. We tested this assumption formally using the fully flexible model for parallel paths proposed by Mora and Reggio (2017); our sample met this identifying assumption. Results available on request. All the variables included are described in appendix 6.
} 
The coefficients of the interaction terms time post $_{\text {it }} * T 1_{\text {it }} \quad\left(\right.$ time $_{\text {post }}{ }_{i t} * T 2_{i t}$ and time post $\left._{i t} * T 3_{i t}\right)$ measure the causal effect on electricity consumption of treatment 1 , treatment 2 , and treatment 3 i.e. the effect of an ambitious goal and boosts, a modest goal and boosts, and only boosts.

The full set of controls for the observable characteristics includes two vectors. The vector Individual characteristics includes variables describing the respondent's environmental habits and some individual data such as age, profession, NEP scale score, GEB items and environmental commitment. The total number of people in the household (adults and children) is a non-neutral variable and is related to the family's everyday habits (Gram-Hanssen, 2014). The generational impact of age has also been shown to be important (Chancel, 2014).

Dwelling characteristics includes variables for number of people in the household, dwelling surface area, and type of heating system. Following Gram-Hanssen (2014), we use household size rather than electricity consumption per square meter as an explanatory variable for electricity consumption.

Since we are estimating electricity consumption during a period of time which involves a change of season (winter to spring) it is important to consider outside temperature changes. Kavousian et al. (2013) show the importance of outside temperatures for explaining residential electricity use; therefore, we include in our model the variable weather temperature as a $\operatorname{control}^{11} \cdot \varepsilon_{i t}$ is a random, unobserved term which contains the errors due to omitted covariates.

\section{Data and sample characteristics}

Table 2 presents the characteristics of the sample that completed the ex-ante and ex-post questionnaires and are permanent residents.

\footnotetext{
11 The variable weather temperature corresponds to the average monthly temperature in the Principality and proxies for exogenous climatic conditions in our estimation. Appendix 4-a shows the evolution of the weather during the period of analysis i.e., June 2018 to May 2019. The square of weather temperature is used in the econometric estimation. The average temperature decreases during the winter (October to January) and explains the significant effect on electricity consumption observed in the regression analysis.
} 
Table 2: Sample description $(\mathrm{N}=77)$

\begin{tabular}{|c|c|c|c|c|}
\hline Variables & Mean & Std. Dev. & Min & Max \\
\hline Men & 0.594 & 0.491 & 0 & 1 \\
\hline Age (45-55 years old) & 0.300 & 0.459 & - & - \\
\hline Monegasque nationality & 0.501 & 0.500 & 0 & 1 \\
\hline French nationality & 0.125 & 0.330 & 0 & 1 \\
\hline Italian nationality & 0.224 & 0.417 & 0 & 1 \\
\hline Owner & 0.434 & 0.495 & 0 & 1 \\
\hline Single & 0.332 & 0.471 & 0 & 1 \\
\hline Married & 0.667 & 0.471 & 0 & 1 \\
\hline Post-secondary diploma & 0.168 & 0.374 & 0 & 1 \\
\hline License (secondary diploma) & 0.135 & 0.341 & 0 & 1 \\
\hline Master / Engineer & 0.360 & 0.480 & 0 & 1 \\
\hline Employee & 0.263 & 0.440 & 0 & 1 \\
\hline Higher intellectual professions & 0.151 & 0.358 & 0 & 1 \\
\hline Retired & 0.310 & 0.463 & 0 & 1 \\
\hline Surface (area) $\left(\mathrm{m}^{2}\right)$ & 102.010 & 46.402 & 30 & 250 \\
\hline No. of inhabitants (persons) & 2.227 & 1.110 & 0 & 5 \\
\hline High NEP & 0.51 & 0.50 & 0 & 1 \\
\hline Belonging to a green NGO & 0.095 & 0.29 & 0 & 1 \\
\hline Individual heating system & 0.574 & 0.494 & 0 & 1 \\
\hline Previous participation in an experiment & 0.088 & 0.284 & 0 & 1 \\
\hline Individual electric heating system & 0.419 & 0.493 & 0 & 1 \\
\hline Prewash & 3.945 & 1.747 & 0 & 5 \\
\hline Full load in washing machine & 4.297 & 1.159 & 0 & 5 \\
\hline Turn off heating at night & 2.364 & 2.252 & 0 & 5 \\
\hline Turn on heating to avoid wearing thick clothing & 1.391 & 1.584 & 0 & 5 \\
\hline Reduce heating if absent for more than 4 hours & 2.932 & 2.178 & 0 & 5 \\
\hline Turn off lights in unoccupied rooms & 4.608 & 0.8194 & 0 & 5 \\
\hline Average electricity consumption $(\mathrm{kWh})$ & 318.461 & 196.073 & 2.89 & 1659.60 \\
\hline
\end{tabular}

Socio demographic and household characteristics. In terms of gender and age distribution, men are slightly overrepresented (60\%) in our sample. On average, respondents were aged between 46 and 55 years $(30 \%)$ similar to the Monegasque average age (46.6 years). Our sample is composed of citizens who are working (70\%), $26.3 \%$ as employees and $15.1 \%$ professionals. The average number of people per dwelling is 2.2 which is line with the average for the whole Principality ${ }^{12}$, and $43 \%$ of participants own their dwelling.

${ }^{12}$ The Monaco en chiffres /Monaco in figures (2019) report shows that there are $37.8 \%$ single person households, $32.3 \%$ two-person households, and $14.6 \%$ of households that include three (or more)individuals. 
Household's environmental concerns. We use the short version of the NEP scale (Davis et al., 2009; Schleyer-Lindenmann et al., 2016) to create a proxy variable for NEP score ( $M=1.78$, $\mathrm{Sd}=0.82$. Med $=23$ ). Volunteers with an average NEP score below the median are considered less concerned about and less sensitive to environmental issues (Low NEP); volunteers with an average NEP score above the median are considered the most sensitive to environmental issues (High NEP) ${ }^{13}$. The dummy variable High NEP/Low NEP allows us to investigate the potential correlation between environmental concern and environmental behavior which Davis et al. (2009) assume. Our sample includes some low NEP profiles (49\%) and a significant proportion of high NEP profiles $(51 \%)$.

\section{Table 3: Environmental concern profiles}

\section{Energy behaviors.}

The volunteers responded to five items on energy behavior from the GEB scale (Kaiser and Biel 2000) $)^{14}$. We added a question about membership of an environmental $\mathrm{NGO}^{15}$. $64 \%$ of the sample reported collecting laundry to make enough for a full washing machine load, and $65 \%$ said they did not use the pre-wash program. 57\% of dwellings had an individual heating system and $42 \%$ were on a shared system. Half (49\%) of our sample had electric heating systems. 52\% used eco-efficient light bulbs, and 32.93\% used standard light bulbs, and $76.02 \%$ said they

\begin{tabular}{|c|c|c|c|c|c|}
\hline & \multicolumn{5}{|c|}{ Treatment } \\
\hline NEP Profile & $\begin{array}{c}\text { Boost \& ambitious } \\
\text { goal (T1) }\end{array}$ & $\begin{array}{c}\text { Boost \& } \\
\text { modest goal (T2) }\end{array}$ & $\begin{array}{c}\text { Boost only } \\
(\mathrm{T} 3)\end{array}$ & $\begin{array}{c}\text { Control } \\
\text { group (CG) }\end{array}$ & Total \\
\hline High NEP & $44 \%$ & $67 \%$ & $45 \%$ & $52 \%$ & $51 \%$ \\
\hline Low NEP & $56 \%$ & $33 \%$ & $55 \%$ & $48 \%$ & $49 \%$ \\
\hline Total & $100 \%$ & $100 \%$ & $100 \%$ & $100 \%$ & $100 \%$ \\
\hline
\end{tabular}

turned off lights in unoccupied rooms. $10 \%$ of participants were members of a green NGO.

\footnotetext{
${ }^{13}$ Internal consistency for the NEP scale is shown by a coefficient alpha of 0.87 , suggesting relatively high internal consistency of the items. A reliability coefficient of 0.70 or higher is considered acceptable. The reliability coefficient corresponds to the usual results for this type of scale for instance, alpha= 0.75 in Davis et al. (2011).

${ }^{14}$ Our choice to use only 5 items from the GEB scale was to increase the chances that respondents would complete the questionnaire. Respondents were asked to indicate their level of agreement with each of the items as: "never", "seldom", "sometimes", "often", "always". The responses were scored from 1 to 5 from never to always (see appendix 5).

${ }^{15}$ Are you currently a member of an NGO working on sustainable development or environmental protection? (Q36).
} 


\section{Results}

\subsection{Evolution of electrical consumption across treatments}

Table 4: Electricity consumption statistics before and during the field experiment

\begin{tabular}{|c|c|c|c|c|c|}
\hline Treatment & $\begin{array}{l}\text { Average energy } \\
\text { consumption per } \\
\text { household during } \\
\text { the pre-treatment } \\
\quad \text { period (a) }\end{array}$ & $\begin{array}{l}\text { Average energy } \\
\text { consumption per } \\
\text { household during } \\
\text { the treatment period } \\
\text { (b) }\end{array}$ & $\begin{array}{l}\text { Difference }(\%) \\
\text { (c) }\end{array}$ & $\begin{array}{c}\text { Diff-in-Diff } \\
\text { (\%) } \\
\text { (d) }\end{array}$ & $\begin{array}{c}\text { Pvalue } \\
\text { (e ) }\end{array}$ \\
\hline $\begin{array}{c}\text { Boost \& ambitious } \\
\text { goal (T1) }\end{array}$ & $329.22 \mathrm{kWh}$ & $369.11 \mathrm{kWh}$ & $12 \%$ & $-19 \%$ & $0.0778 *$ \\
\hline $\begin{array}{c}\text { Boost \& modest } \\
\text { goal (T2) }\end{array}$ & $236.34 \mathrm{kWh}$ & $252.47 \mathrm{kWh}$ & $7 \%$ & $-24 \%$ & $0.0177 * *$ \\
\hline Boost only (T3) & $295.00 \mathrm{kWh}$ & $343.49 \mathrm{kWh}$ & $16 \%$ & $-15 \%$ & 0.1237 \\
\hline Control (CG) & $314.96 \mathrm{kWh}$ & $412.67 \mathrm{kWh}$ & $31 \%$ & - & - \\
\hline Average of the panel & $296.71 \mathrm{kWh}$ & $352.82 \mathrm{kWh}$ & $18.91 \%$ & & \\
\hline \multicolumn{6}{|c|}{$\begin{array}{l}\text { Note: Column (a) is average electricity consumption by treatment in kWh during the } 6 \text { months before the start of the experiment, June } \\
2018 \text { to November } 2018 \text {. Column (b) is average electricity consumption by treatment during the } 6 \text { months of the experiment December } \\
2018 \text { to May } 2019 \text {. Column (c) is based on treatment and shows the difference in average energy consumption between the two periods } \\
\text { i.e., during the experiment period minus the average consumption in the } 6 \text { months before the experiment in percentage. Column (d) shows } \\
\text { the percentage variation (between the periods and with respect to the control group) in the percentage of variation in the control group } \\
\text { (CG). Column (e) presents the results of a t-test of the difference between the average consumptions of the treated groups compared to } \\
\text { the control group. }\end{array}$} \\
\hline
\end{tabular}

Table 4 presents the descriptive statistics for electricity consumption across the four treatments ${ }^{16}$. Average monthly electricity consumption shows that the group which consumed the least electricity was the boost and modest goal treatment, followed by the boost only treatment.

Table 4 column (c) presents the variation (as a percentage) in households' average electricity consumption across the four treatments. We observe a similar trend of increased average electricity consumption during the period of the experiment for all treatments due to the winter months. We control for this in our econometric model. Highest consumption was by the control group: CG $31 \%$ increase in consumption compared to the average consumption of the whole sample. The T1 and T2 groups had the lowest increases at respectively $12 \%$ and $7 \%$. A Kruskal

\footnotetext{
${ }^{16}$ The statistics are based on average electricity consumption. The SMEG data are seasonally adjusted data; SMEG data do not distinguish between electricity used for heating and other electricity consumption. The results of table 4 are preliminary statistical estimations to be confirmed (or not) in the later econometric analysis.
} 
Wallis (K-Wallis) ${ }^{17}$ equality test of average monthly electricity consumption among treatments confirms that average electricity consumption during the six months of the observation period differed significantly across treatments $(\mathrm{p}$-value $=0.0001$ ). Also, pairwise comparison by treatment based on a Wilcoxon-Mann-Whitney (WMW) test shows that average electricity consumption over the period of the experiment differed significantly across some treatments ( $p=0.0001$ ) although the consumption of the pair T3-CG shows no differences during the two first months of the experiment $(\mathrm{p}=0.495)^{18}$.

\subsection{Efficiency of combination of boosts and goals}

Table 5 presents the results of the DID regression for changes to household electricity consumption ${ }^{19}$.

\footnotetext{
${ }^{17}$ Since the distribution of the error terms of our dependent variable does not satisfy the normal distribution criteria, we rely on the K-Wallis and WMW tests as alternatives to one-way analysis of variance (ANOVA). These two non-parametric tests are considered the best alternatives to the traditional $t$ test which requires a normal distribution of the tested variable error terms. The K-Wallis test is used to compare two or more independent samples of equal or different sizes. It is an extension of the MWM U test which is used to compare two groups.

${ }^{18}$ Since the WMW test computes the comparison using the median, we add a pairwise comparison by treatment using the regular $t$ test which compares average electricity consumption. The results show similar effects: $\mathrm{T} 1 \mathrm{vs}$ $\mathrm{CG}$ pvalue $=0.077, \mathrm{~T} 2$ vs $\mathrm{CG}$ pvalue $=0.017, \mathrm{~T} 3$ vs $\mathrm{CG}$ pvalue $=0.123$.

${ }^{19}$ Based on the analytic using one-sided power calculations for DID models (Burling et al., 2020) and assuming $\alpha=0.05$ and a MDE of 0.7 , we observe a minimum effect size of 0.05 for the treatment effects results presented in this study
} 


\section{Table 5: Difference-in-differences estimation results}

Average household energy

consumption

(column a)
Average household energy consumption

(column b)

$\begin{array}{cc}54.17 * * & 54.17 * * \\ 3.152 & -15.11 \\ -46.84 & -69.53 \\ -38.08 & -70.39 \\ R e f & R e f \\ -56.10^{*} & -56.10^{*} \\ -71.63 * * & -71.63 * * \\ -43.22 & -43.22\end{array}$

time ( time $_{\text {post }_{i t}}$

Boost \& ambitious goal $\left(T 1_{i}\right)$

$-6.53$

Boost \& modest goal $\left(T 2_{i}\right)$

$-70.39$

Boost only $\left(T 3_{i}\right)$

time*T1 ( time $_{\text {post }}$ it $* T 1_{i t}$ )

. $10^{*}$

time*T2 (time $\left._{\text {post }_{i t}} * T 2_{i t}\right)$

Individual characteristics

Age

Higher intellectual profession

$-72.59$

$-53.69$

Employee

0.309

18.30

Retired

$-9.119$

5.78

Household size

$48.54 *$

47.44

High NEP

$-22.99$

$-8.61$

Being part of Env. association

Dwelling' characteristics

Surface area

Individual electric heating system

Energy curtailment behaviors

Prewash

Full washing machine

Turn off heating at night

Turn on heating to avoid wearing thick clothing

16.13

Reducing heating for absences of more than 4 hours

Turn off lights in unoccupied rooms

Table 5 presents the DID ordinary least square estimations equivalent to the regression formulation. The interaction variables time*T1, time*T2, time*T3 represent the effect of the treatments T1, T2, T3 compared to the control group (CG). Robust standard errors are clustered by household. Coefficient statistical significance is $* * * \mathrm{p}<0.01, * * \mathrm{p}<0.05, * \mathrm{p}<0.1$. Column a presents the treatment effect estimation without curtailment behaviors, Column b includes all GEB scale items and membership of an environmental NGO. 
Table 5 compares the treated and control groups. ${ }^{20}$ First, the coefficients of the interaction variables "time*T1" and "time*T2" for the effect of the treatments during the period of observation are negative and significant. Thus, T1 and T2 reduce household electricity consumption by respectively $56.10 \mathrm{kWh}$ and $71.63 \mathrm{kWh}$ compared to the control group (CG). The coefficient of the interaction "time*T3" is not significant, meaning that the treatment "boosts only" (T3) does not affect household electricity consumption.

Second, electricity consumption is positively and significantly affected by household size (column a) and use of an individual heating system. Intuitively, the size of the household will have a positive effect on electricity use ( $48.54 \mathrm{kWh}$ on average) and households with individual electric heating systems consume $114.9 \mathrm{kWh}$ more on average than those with a shared heating system. Also, electricity consumption changes based on the weather conditions i.e. higher outside temperatures and more light lead to a reduction in use of heating and lighting in the house and decrease electricity consumption. Household size has a significant and positive impact on electricity consumption i.e. larger household size (more individuals in the household) is related to higher electricity consumption.

Estimating the detailed treatments effects based on the quarterly data reveals some interesting features (appendix 7). Specifically, boosts on their own have small but significant effects on energy behavior after some time whereas boosts combined with goals have an immediate and stronger effect on reducing electricity consumption. Precisely, during the first three months and compared to the control group, an ambitious goal plus boosts (T1) reduces electricity consumption by $81.12 \mathrm{kWh}$ on average while a modest goal plus boosts (T2) reduces consumption by $90.09 \mathrm{kWh}$ on average. Both these effects disappear in the second three months of the experiment. Households in the T3 group which received only boosts showed an average reduction in their electricity consumption in the second three months of $34.01 \mathrm{kWh}$. These differences can be explained by the novelty of having a goal to work towards which resulted in higher commitment in the first three months of the experiment. Alternatively, the time taken to learn from the boosts (without a goal) (T3) is reflected in the fact that the energy reductions showed up only in the second three months of the experiment. These findings highlight the need to motivate participants continuously to avoid loss of interest in trying to reduce their electricity usage.

\footnotetext{
${ }^{20}$ Due to some missing values for the variable "number of inhabitants", we reduced the number of observations to 708. We ran the estimations including and the results did not change. However, we prefer to present the estimations with no missing values.
} 
The treatments that produced the best results were boosts plus goals (T1 and T2) which had significant effects on reducing electricity consumption. To investigate whether NEP scores played a part, we estimate DID for two different sub-samples of individuals based on their different NEP profiles. This allows us to identify for which groups the treatments had a stronger effect and to compare the effect based on high NEP or low NEP profile. 
Table 6: Treatments estimation with the NEP profile

\begin{tabular}{|c|c|c|}
\hline VARIABLES & $\begin{array}{l}\text { Average household } \\
\text { electricity consumption } \\
\text { (high NEP) (a) }\end{array}$ & $\begin{array}{l}\text { Average household electricity } \\
\text { consumption } \\
\text { (low NEP) (b) }\end{array}$ \\
\hline time $\left(\right.$ time $_{\text {post }}$ it $)$ & $69.97 * * *$ & 30.80 \\
\hline Boost \& ambitious goal $\left(T 1_{i}\right)$ & $-62.4 * * *$ & $75.00 * * *$ \\
\hline Boost \& modest goal $\left(T 2_{i}\right)$ & $-140.3 * * *$ & $-60.51 *$ \\
\hline Boost only $\left(T 3_{i}\right)$ & $-72.00 *$ & -7.244 \\
\hline Control $\left(C G_{i}\right)$ & Ref & Ref \\
\hline time*T1 $\left(\right.$ time $\left._{\text {post }_{i t}} * T 1_{i t}\right)$ & $-80.33 * *$ & -27.73 \\
\hline time*T2 $\left(\right.$ time $\left._{\text {post }_{i t}} * T 2_{i t}\right)$ & $-96.04 * * *$ & -47.29 \\
\hline time*T3 $\left(\right.$ time $\left._{\text {post }}{ }_{i t} * T 3_{i t}\right)$ & -62.47 & -9.134 \\
\hline \multicolumn{3}{|l|}{ Individual characteristics } \\
\hline Age (45-55 years old) & $-81.36 * * *$ & $-125.9 * * *$ \\
\hline Higher intellectual profession & $-280.3 * * *$ & $-170.1 * * *$ \\
\hline Employee & $-197.9 * * *$ & -13.65 \\
\hline Retired & 36.27 & $-450.5 * * *$ \\
\hline Household's size & $36.60 * * *$ & -9.398 \\
\hline Membership of an environmental NGO & $-150.4 * * *$ & $-232.9 * * *$ \\
\hline \multicolumn{3}{|l|}{ Dwelling characteristics } \\
\hline Surface area & $1.182 * * *$ & -0.245 \\
\hline Indiv electric heating system & 14.78 & $197.9 * * *$ \\
\hline \multicolumn{3}{|l|}{ Curtailment behaviors } \\
\hline Prewash & $29.96^{* * *}$ & $-23.17 * * *$ \\
\hline Full washing machine & $-23.24 * *$ & $80.88^{* * *}$ \\
\hline Turn off heating at night & -7257 & -0.505 \\
\hline Turn on heating to avoid wearing thick clothing & $11.98 *$ & $14.07 * *$ \\
\hline Reducing the heating for 4 hours absence & -9.2444 & $-8.781^{*}$ \\
\hline Turn off the lights in unoccupied rooms & $-96.17 * * *$ & -11.15 \\
\hline Weather temperature & $-0.249 * * *$ & -0.0914 \\
\hline Constant & $-1064 * * *$ & $-284.2 * * *$ \\
\hline Observations & 360 & 348 \\
\hline R-squared & 0.636 & 0.589 \\
\hline
\end{tabular}

Table 6 presents the DID estimations for the equivalent regression formulations for the effect of the treatment. The sample is divided into high level of concern for the environment ( $n=39$ households observed) and low level of concern for the environment ( 38 households observed). Columns (a) and (b) report the respective ordinary least square estimates for the first and second groups. Robust standard errors are clustered by household. Coefficient statistical significance is based on the standard thresholds $* * * \mathrm{p}<0.01, * * \mathrm{p}<0.05, * \mathrm{p}<0.1$.

The results in table 6 show the impact of the NEP profile. Column (a) shows the estimated impact of the treatments for the high NEP profile. For this profile, T1 and T2 are effective for reducing electricity use. If we compare the impact of the three treatments, $\mathrm{T} 2$ boosts and modest goal has the strongest effect and reduces electricity consumption by $96.04 \mathrm{kWh}$ on average 
(compared to the control group). T1 comes next with $80.33 \mathrm{kWh}$ electricity consumption reduction. In this profile, a professional job, being retired, or belonging to an environmental association increases the chances of reducing electricity consumption. Using an individual electric heating system does not increase electricity consumption significantly which suggests that a high NEP profile is related to better management of electricity use.

Column (b) presents the treatments effect for low NEP and shows that this group is not significantly sensitive to any of the treatments. For the low NEP profiles, some curtailment behaviors such as not using the prewash program, are significant for reducing electricity consumption - $23.17 \mathrm{kWh}$ on average. In addition, being retired and having more time, and membership of an environmental NGO have a positive impact on reducing electricity consumption, showing some other forms of environmental citizenship for this profile. If we compare high and low NEP profiles, we observe the same effects for most of the control variables. However, use of an individual electric heating system is positively significant for the low NEP profile. Households with a low NEP profile consume more electricity (197.9 kWh on average) if they have an individual electric heating system.

Overall, our results confirm those obtained from our main regression, and more precisely that a combination of goals and boosts is more relevant for lowering household electricity consumption. However, the efficiency of the treatments depends on the NEP profile. Households with a high NEP profile are more likely than low NEP profile households to reduce their electricity consumption.

\section{Discussion}

Our empirical findings are fourfold. First, when implemented in combination with a goal (ambitious or modest), boosts can have a significant effect on reducing electricity use. In other words, setting a precise goal and providing boosts incentivizes the household to act and to reduce its electricity consumption. That is, a boost increases the household's knowledge about electricity usage and providing suitable means for steering households in the presence of goals (Martela, 2015). In this case, boosts and goals seem to be mutually reinforcing. That is, the combination of a modest (realistic) goal and boosts produces more significant results than a more ambitious goal and boosts. Therefore, a step-by-step strategy with a long-term perspective delivers better outcomes. These results are in line with the findings in Harding and Hsiaw (2014) on the need to set realistic goals. 
Second, although boost only (treatment T3) reduces electricity use, this result is not statistically significant for any profile. This is in line with Abrahamse et al. (2005) who recommend combining behavioral tools with goal setting. We extend this idea by combining goal setting with boosts which have long lasting effects on knowledge. If we focus only on boosts, we find this is effective for high NEP households but not significant for low NEP households. This exemplifies the complexity of the causality link between ecological concern and electricity behaviors shown by Nauges and Wheeler (2017). It also emphasizes the need to combine boosts with an objective span and to implement these behavioral tools in the right context.

Third, in the case of high NEP profiles, our results show that all the treatments promote electricity saving. Being retired, being a professional, and belonging to a green NGO appear to be important for promoting electricity saving. These relations suggest that individuals with more time will be more likely to have the resources and motivation to change their electricity use behavior and that higher education and greater environmental commitment are good predictors of such actions. Although the findings from our behavioral treatments are novel, the empirical findings on the effect of education and retirement (having more time) are in line with prior results. For instance, Pullinger (2014) shows that working time, sustainable consumption and well-being should be considered together. More precisely, being retired or having shorter working hours has a positive effect on sustainable consumption by allowing the household more time to learn and providing the enabling conditions to study the environment and act on it (for a similar discussion see Shove et al., 2020).

Fourth, among low NEP profiles, we found that none of the treatments were significant although education, retirement, environmental commitment, and curtailment behaviors (variable "prewash") matter. This result is in line with the findings in Nauges and Wheeler (2017) on the difference between curtailment and energy efficient behaviors. The latter explain why the relationship between curtailment behavior and concern for climate change is difficult to identify and requires long learning combined with non-monetary and monetary tools to increase its potential efficiency. In the case of citizens with low intrinsic motivation towards environmental issues, some other forms of environmental commitment are at work. These findings also illustrate the complexity between electricity behaviors and environmental concern and the dependence on dwelling characteristics and diverse forms of actions beyond solely green values (Welsch and Kuhling, 2009; Woersdorfer and Kaus, 2011; Babutsidze and Chai, 2018). 
More generally, following the recommendations in Buckley (2020) and Ander and Fels (2018), we provide new evidence on the effectiveness of boosts and goals for driving potential electricity reductions. In Monaco and elsewhere, there is an urgent need to increase electricity use transparency through the provision of information and education and by "increasing means and reducing barriers to increase capability or opportunity" (Belaid and Joumni, 2020: 9). Thus, studying the effectiveness of goals combined with boosts is relevant to increase individual capability to transform a stated concern for the environment into concrete action. Our results show that modest goals combined with specific information can translate concern for the environment into green behavior. A goal of between a $15 \%$ and $25 \%$ reduction in energy use is efficient for households already concerned about the environment and committed to greener behaviors.

\section{Conclusions and policy implications}

Boosts seem to be a promising and novel tool which require some pre-conditions before being implemented. Goal setting is a classic tool which has good outcomes and a greater impact when combined with other tools. Our results show the effect of goals and boosts on energy conservation, and their complementarity and effectiveness for steering individuals to reduce their electricity consumption. Outcomes for high NEP profile households show their inherent limits which policy makers should consider if they want to change individual behaviors. Let's elaborate further these points.

Our empirical findings highlight that there are no good or bad behavioral tools but only instruments adapted to a local context and targeted to a specific population (Bradt, 2019). Our field work showed that the right combination of a modest goal and boosts can produce significant results. This suggests that researchers and policy makers should not overlook the importance of instruments such as goal setting and focus only on boosts; on the contrary, they need to observe the focal population to determine whether goals combined with boosts will produce better results, and why. Having chosen a particular behavioral tool, it may be necessary to find the goal level and to co-design this process with local actors. Here knowledge of the field and the level of trust among the participants will be critical (see Kendel et al., 2017 for a suggested balance). 
It is important also to determine what participants consider to be a realistic and an ambitious goal. An ambitious goal involves the degree of pressure that can be exerted on individuals and the length of time that they will be able to sustain this effort. Our research in the field shows that volunteers set an ambitious goal were initially highly motivated but found it difficult to maintain this level of effort over the long run which shows that extrinsic motivation has limits. However, several goal levels should be tested to establish which provides the most significant results. Sample size and other conditions matter for the goals levels set in experiments.

Finally, it is well known that environmental profile matters. The fact that those most involved in environmental issues are the most responsive to behavioral tools, creates new problems related to inclusiveness. As Hertwig and Ryall (2020) point out, the notion of emancipation through education, and increasing individual capabilities are both important and may increase the pressure to innovate to include all citizens in an ecological-transition-for-all agenda (DellaValle and Sareen, 2020). Economists and decision-makers must study these new behavioral tools to identify which will include the largest range of the population, and replicate experience in different and larger contexts to obtain robust results. This requires both ambitious but cautious efforts since each context is unique, and some tools may work only in certain contexts. This leads to the limitations of our study.

The evidence on the efficacy of combining boosts with goals raises questions about behavioral strategies and their enforcement. We need more in-depth investigation of the efficiency of behavioral tools for promoting electricity saving behaviors which considers the different levels of households' concern for the environment. To increase its generalizability to other fields such as mobility and nutrition, and to investigate the right combination of behavioral tools, (see Banerjee and Duflo, 2009) our field experiment should be replicated with a larger sample and a more diverse populations of volunteers. We also cannot exclude a Hawthorne effect (Schwartz et al., 2013) i.e., the fact of being observed increasing motivation and possible biasing our 
results. These limitations are discussed in Harrison and List (2004) and are important. For instance, in some field experiments the control group is not neutral. This is highlighted by Kendel et al. (2017) in the context of their experiment on electrical consumption and their finding of $13 \%$ decreased energy use in the control group and a $26 \%$ decrease in the treatment groups. This suggests that being observed may induce some behavioral changes in some contexts. In our experiment, we cannot exclude a framing effect on the volunteers. For example, the ex-ante survey asked about energy systems and heating, some energy practices, and environmental concerns and may have influenced the sample by revealing some implicit assumptions of our experiment. These limitations are inherent to a field experiment methodology and are both a force and a constraint and may moderate some results (see Harrison and List 2004 for a longer discussion). 


\section{References}

Abrahamse, W., Steg, L., Vlek, C., \& Rothengatter, T. (2005). A review of intervention studies aimed at household energy conservation. Journal of Environmental Psychology, 25, 273-291.

Allcott, H., \& Rogers, T. (2014). The short-run and long-run effects of behavioral interventions: Experimental evidence from energy conservation. American Economic Review, 104(10), 3003-37.

Andor, M. A., \& Fels, K. M. (2018). Behavioral economics and energy conservation-a systematic review of nonprice interventions and their causal effects. Ecological Economics, 148, 178-210.

Angrist, J. D., \& Pischke, J. S. (2008). Mostly harmless econometrics: An empiricist's companion. Princeton University Press.

Babutsidze, Z., \& Chai, A. (2018). Look at me saving the planet! The imitation of visible green behavior and its impact on the climate value-action gap. Ecological Economics, 146, 290-303.

Banerjee, A., V, \& Duflo, E. (2009). L'approche expérimentale en économie du développement, Revue d'économie politique, 119(5), 691-726.

Baum, C. M., \& Gross, C. (2017). Sustainability policy as if people mattered: developing a framework for environmentally significant behavioral change. Journal of Bioeconomics, 19(1), 53-95.

Belaïd, F., \& Joumni, H. (2020). Behavioral attitudes towards energy saving: Empirical evidence from France. Energy Policy, 140, 111406.

Bradt, J. (2019). Comparing the effects of behaviorally informed interventions on flood insurance demand: an experimental analysis of 'boosts' and 'nudges'. Behavioural Public Policy, 1-31.

Buckley, P. (2020). Prices, information and nudges for residential electricity conservation: A meta-analysis. Ecological Economics, 172, 106635.

Charlier, C., Guerassimoff, G., Kirakozian, A., \& Selosse, S. (2020). Under pressure! Nudging electricity consumption within firms. Feedback from a field experiment. The Energy Journal, 42(1).

Davis, J. L., Green, J. D., \& Reed, A. (2009). Interdependence with the environment: Commitment, interconnectedness, and environmental behavior. Journal of environmental psychology, 29(2), 173-180.

DellaValle, N., \& Sareen, S. (2020). Nudging and boosting for equity? Towards a behavioural economics of energy justice. Energy Research \& Social Science, 68, 101589.

Dolan, P., Hallsworth, M., Halpern, D., King, D., \& Vlaev, I. (2010). MINDSPACE: influencing behaviour for public policy. Institute of Government, London, UK.

Dolan, P., Hallsworth, M., Halpern, D., King, D., Metcalfe, R., \& Vlaev, I. (2012). Influencing behaviour: the mindspace way. Journal of Economic Psychology, 33, 264-277

Dunlap, R. E., Van Liere, K. D., Mertig, A. G., \& Jones, R. E. (2000). New trends in measuring environmental attitudes: measuring endorsement of the new ecological paradigm: a revised NEP scale. Journal of social issues, 56(3), 425-442.

EEA (2019), Progress on energy efficiency in Europe: indicator assessment, ENR (037)

Gandhi, R., Knittel, C. R., Pedro, P., \& Wolfram, C. (2016). Running randomized field experiments for energy efficiency programs: A practitioner's guide. Economics of Energy \& Environmental Policy, 5(2), 7-26.

Gigerenzer, G., Todd, P. M. et al. (1999), Simple Heuristics that make Us Smart, New York: Oxford University Press.

Gram-Hanssen, K. (2014). Existing buildings-Users, renovations and energy policy. Renewable Energy, 61, 136140.

Grüne-Yanoff, T., \& Hertwig, R. (2016). Nudge versus boost: How coherent are policy and theory? Minds and Machines, 26(1-2), 149-183.

Grüne-Yanoff, T., Marchionni, C., \& Feufel, M. A. (2018). Toward a framework for selecting behavioural policies: How to choose between boosts and nudges. Economics \& Philosophy, 34(2), 243-266. 
Harding, M., \& Hsiaw, A. (2014). Goal setting and energy conservation. Journal of Economic Behavior \& Organization, 107, 209-227.

Hargreaves, T., Nye, M., \& Burgess, J. (2013). Keeping energy visible? Exploring how householders interact with feedback from smart energy monitors in the longer term. Energy policy, 52, 126-134.

Harrison, G. W., \& List, J. A. (2004). Field experiments. Journal of Economic literature, 42(4), 1009-1055.

Hertwig, R., \& Grüne-Yanoff, T. (2017). Nudging and boosting: Steering or empowering good decisions. Perspectives on Psychological Science, 12(6), 973-986.

Hertwig, R., \& Ryall, M. D. (2020). Nudge Versus Boost: Agency Dynamics Under Libertarian Paternalism, The Economic Journal, 130, (629), 1384-1415.

Kahneman, D. (2011). Thinking, fast and slow. London: Penguin Books.

Kaiser, F. G. (1998). A general measure of ecological behavior 1. Journal of applied social psychology, 28(5), $395-422$.

Kaiser, F. G., \& Biel, A. (2000). Assessing general ecological behavior: A cross-cultural comparison between Switzerland and Sweden. European Journal of Psychological Assessment, 16(1), 44.

Kaiser, F. G., Hartig, T., Brügger, A., \& Duvier, C. (2013). Environmental protection and nature as distinct attitudinal objects: An application of the Campbell paradigm. Environment and behavior, 45(3), 369-398.

Karlin, B., Zinger, J.F., Ford, R., (2015). The effects of feedback on energy conservation: a meta-analysis. Psychological Bulletin 141 (6), 1205-1227.

Kavousian, A., Rajagopal, R., \& Fischer, M. (2013). Determinants of residential electricity consumption: Using smart meter data to examine the effect of climate, building characteristics, appliance stock, and occupants' behavior. Energy, 55, 184-194.

Kendel, A., Lazaric, N., Maréchal K., 2017, What do people 'learn by looking' at direct feedback on their energy consumption? Results of a field study in Southern France, Energy Policy, 108, 593-605.

Harding, M., \& Hsiaw, A. (2014). Goal setting and energy conservation. Journal of Economic Behavior \& Organization, 107, 209-227.

Harrison, G.W., List, J.A., (2004). Field Experiments. Journal of Economic Literature 42 (4), 1009-1055.

Hertwig, R. (2017). When to consider boosting: some rules for policymakers. Behavioural Public Policy, 1(2), 143-161.

Hertwig, R. \& Ryall, M.D., (2020) Nudge Versus Boost: Agency Dynamics Under Libertarian Paternalism, The Economic Journal, 130, (629), 1384-415,

Locke E.A. and Latham (2006), New directions in goal-setting theory, Current Directions in Psychological Science, 15 (5), 265-268.

Maréchal, K., and Holzemer, L. (2015). Getting a (sustainable) grip on energy consumption: The importance of household dynamics and 'habitual practices'. Energy research \& social science, 10, 228-239.

Martela, M. (2015). Fallible Inquiry with Ethical Ends-in-View: A Pragmatist Philosophy of Science for Organizational Research, Organization Studies, 36 (4), 537-563

McCalley, L. T., \& Midden, C. J. (2002). Energy conservation through product-integrated feedback: The roles of goal-setting and social orientation. Journal of economic psychology, 23(5), 589-603.

Mora, R., \& Reggio, I. (2017). Alternative diff-in-diffs estimators with several pretreatment periods. Econometric Reviews, 1-22.

My, K. B., \& Ouvrard, B. (2019). Nudge and tax in an environmental public goods experiment: Does environmental sensitivity matter? Resource and Energy Economics, 55, 24-48.

Nauges, C., \& Wheeler, S. A. (2017). The complex relationship between households' climate change concerns and their water and energy mitigation behaviour. Ecological economics, 141, 87-94. 
Pullinger, M. (2014). Working time reduction policy in a sustainable economy: Criteria and options for its design, Ecological Economics, 11-19.

Rebonato, R. (2012). Taking liberties: A critical examination of libertarian paternalism. Palgrave Macmillan.

Reijula, S., \& Hertwig, R. (2020). Self-nudging and the citizen choice architect. Behavioural Public Policy, 1-31.

Schubert, C. (2017). Green nudges: Do they work? Are they ethical? Ecological Economics, 132, 329-342.

Schwartz, S. H., (1992) Universals in the Content and Structure of Values: Theoretical Advances and Empirical Tests in 20 Countries. Advances in Experimental Psychology, 1-65.

Schwartz, D., Fischhoff, B., Krishnamurti, T., Sowell, F., (2013). PNAS 17, 110 (38) 15242-15246

Sen, A., (1999). Commodities and Capabilities, OUP India.

Shove, E., Trentmann, F., Wilk, R., (2020). Time, consumption and everyday life: practice, materiality and culture, Routledge.

Schubert, C. (2017). Green nudges: Do they work? Are they ethical? Ecological Economics, 132, 329-342.

Schleyer-Lindenmann, A., Dauvier, B., Ittner, H., \& Piolat, M. (2016). Mesure des attitudes environnementales : Analyse structurale d'une version française de la NEPS (Dunlap et al., 2000). Psychologie française, 61(2), 83102.

Thaler, R. H., \& Sunstein, C. R. (2008). Nudge: improving decisions about health. Wealth, and Happiness, Yale University Press.

van der Linden, S., Leiserowitz, A., Rosenthal, S., Maibach, E., (2017). Inoculating the Public against Misinformation about Climate Change. Global Challenges, 1 (2), 1600008.

Vassileva, I., Dahlquist, E., Wallin, F., Campillo, J., (2013). Energy consumption feedback devices' impact evaluation on domestic energy use. Applied Energy 106, 314-320.

Welsch, H., \& Kühling, J., (2009). Determinants of pro-environmental consumption: The role of reference groups and routine behaviour. Ecological Economics 69(1), 166-176.

Woersdorfer, J.C., Kaus, W. (2011). Will non owners follow pioneer consumers in the adoption of solar thermal systems? Empirical evidence for north-western Germany. Ecological Economics 70 (12), 2282-2291.

Wood, G., \& Newborough, M. (2007). Energy-use information transfer for intelligent homes: Enabling energy conservation with central and local displays. Energy and buildings, 39(4), 495-503. 


\section{APPENDIX}

Appendix 1-a: Recruitment letter the participants received.

Take part in the Smartlook experience!

Join our CNRS team

Live a unique experience in favor of energy transition

Act for change

- Volunteers' anonymity ensured

- $\quad$ Study launch in June 2018

- Scientific study for non-commercial purposes

\section{THE PROJECT}

According to the Principality of Monaco energy transition White Paper, everyone must act to cut "greenhouse gas emissions by $50 \%$ by 2030 ". Control and reduce energy consumption require individual efforts and changes to habits for better management of energy usage.

We invite you to contribute to the energy transition by participating in Smartlook, a unique scientific study.

Smartlook is a project led by the GREDEG laboratory (Groupe de Recherche en Droit, Economie, Gestion) of the Côte d'Azur University and CNRS, in partnership with the SMEG. It assesses usage of new digital services provided to households in the Principality of Monaco.

Sign up now

via email:

via telephone: XXX

via mail: by returning the reply to coupon to the given address

A project presentation session will be organized to allow you to meet the research team. 
Appendix 1-b: Panel location in the Principality of Monaco

Distribution of the households participating in the field experiment across the Principality.

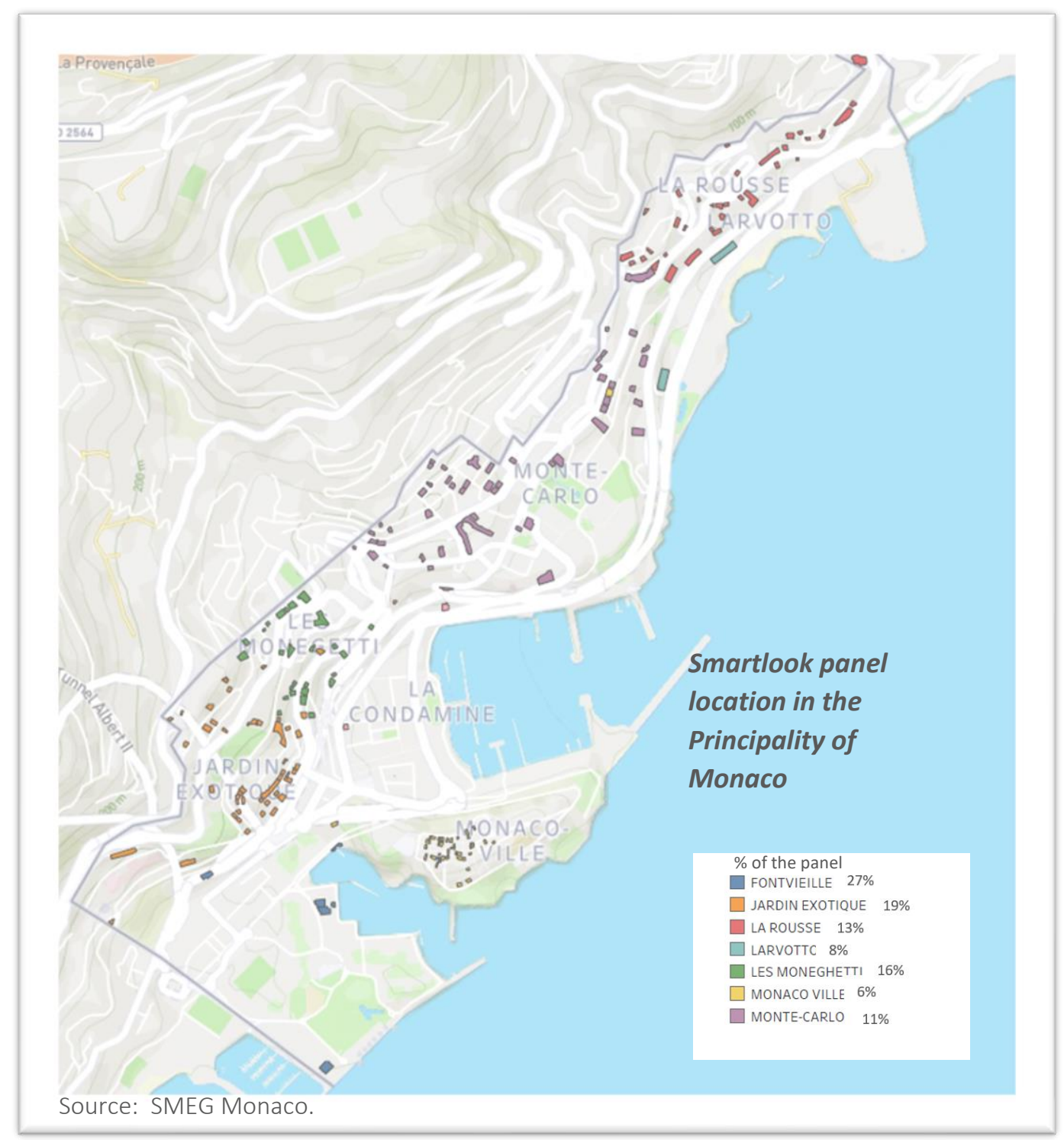




\section{Appendix 2: Boosts sent to citizens}

\begin{tabular}{|c|c|c|}
\hline Boosts & Content & Developed idea \\
\hline Boost 1 & Prepare for winter & $\begin{array}{l}\text { Check insulation in the apartment. } \\
\text { Have boilers cleaned and maintained. }\end{array}$ \\
\hline Boost 2 & A green Christmas & $\begin{array}{l}\text { Check how much electricity Christmas lights are consuming. } \\
\text { Use alternative non-electrical decorations. }\end{array}$ \\
\hline Boost 3 & Do laundry at $30^{\circ}$ & $\begin{array}{l}\text { Check efficiency of washing machine and adjust wash temperatures. } \\
\text { Use energy-efficient drying alternatives. }\end{array}$ \\
\hline Boost 4 & Kitchen appliances (1) & $\begin{array}{l}\text { Check fridge/freezer temperatures, run dishwasher only when full or on an } \\
\text { economy cycle. } \\
\text { Have machines serviced regularly. }\end{array}$ \\
\hline Boost 5 & Kitchen appliances (2) & Try to use energy efficient cooking methods. \\
\hline Boost 6 & Consumption of standby devices & Hidden consumption caused by devices on standby. \\
\hline Boost 7 & Small appliances & Use energy efficient light bulbs. \\
\hline Boost 8 & Prepare for spring $(1 / 2)$ & Spring cleaning tips (1). \\
\hline Boost 9 & Prepare for spring $(2 / 2)$ & Spring cleaning (2). \\
\hline Boost 10 & Use of multi-socket units & Multiple sockets allow more control over individual electrical devices. \\
\hline Boost 11 & Ecolabels & Interpretation of ecological labels on household equipment. \\
\hline Boost 12 & Top tips & Summary of provided tips. \\
\hline
\end{tabular}


Appendix 3- a: Example of boost $n^{\circ} 10$ on use of multi-sockets (English version)

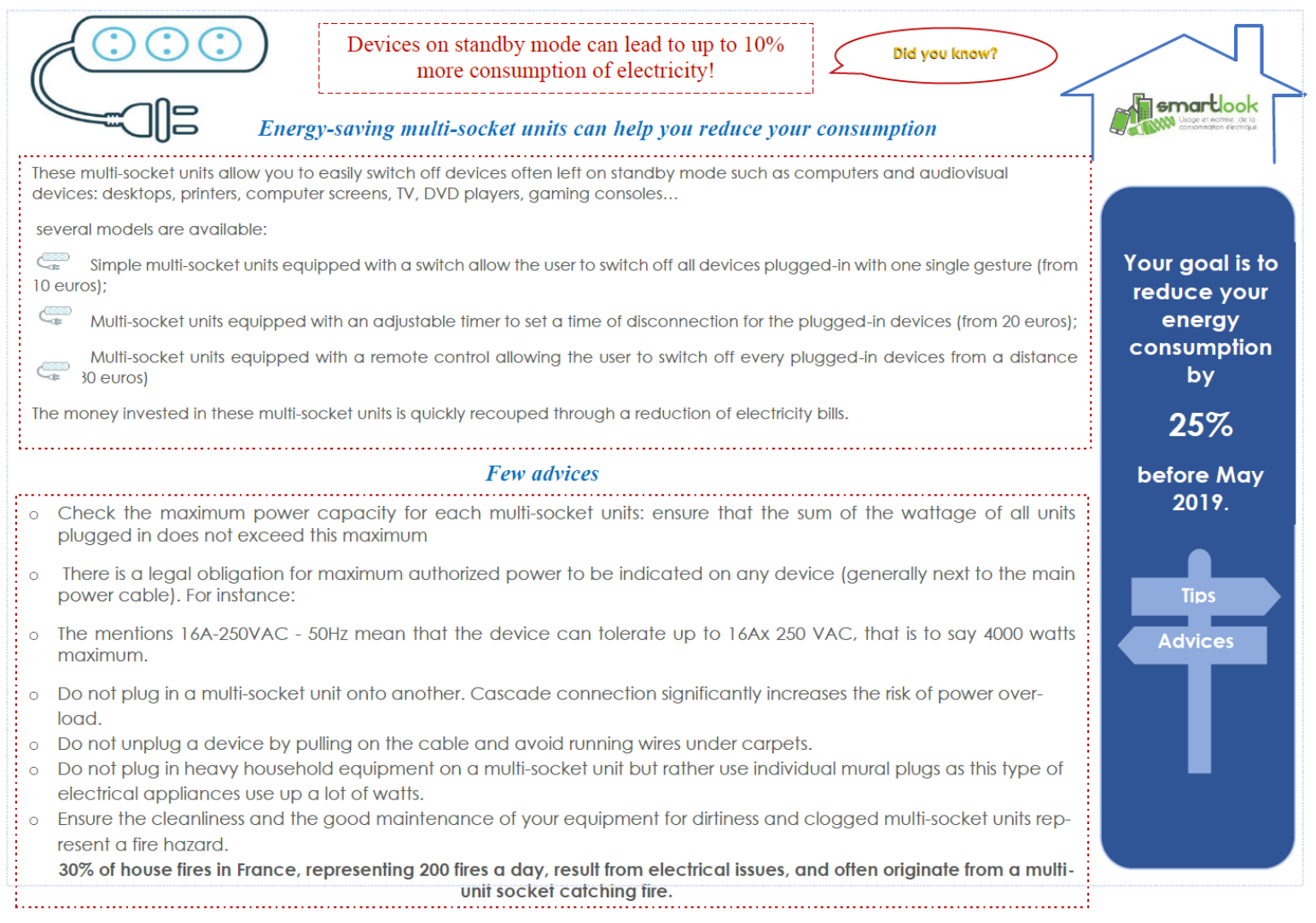

Note: The boosts are phrased in such a way as to draw the attention of the household to a behavior which either is causing unnecessary consumption of energy or would reduce energy consumption. The further information and tips increase the household's knowledge about possible cognitive biases and provide advice on how to overcome them and allow more sustainable consumption of electricity. 


\section{Appendix 3-b: Top tips}
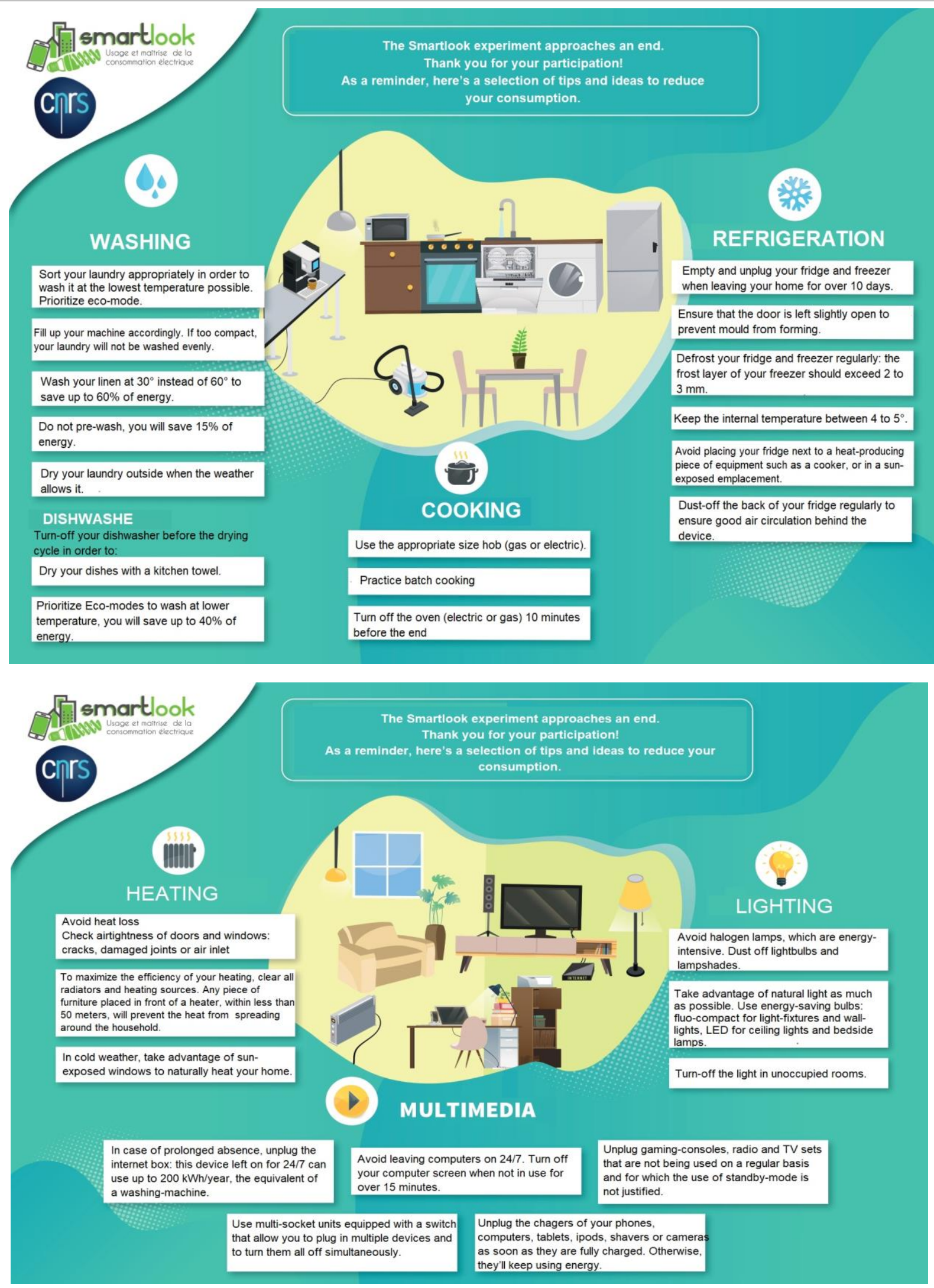
Appendix 4-a. Temperatures changes during the experiment

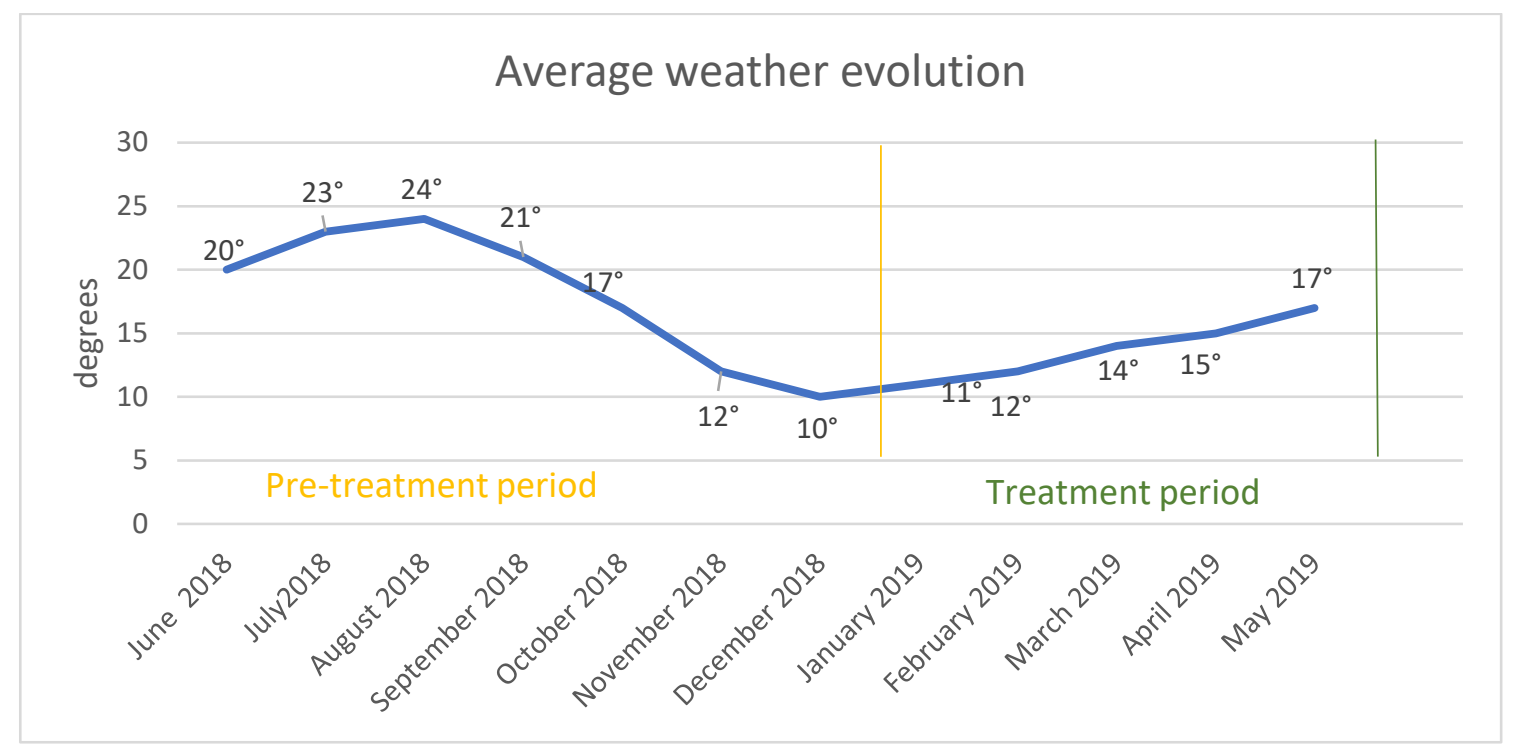

Appendix 4-b. Energy consumption in the Principality of Monaco

Energy consumption in the Principality of Monaco (based on SMEG data on average consumption among Monegasque households).

Energy consumption increased in the panel and in the Principality starting in November 2018. From January 2019 consumption decreased among the households in the panel and the Principality. We believe that the consumption behavior of the panel of households participating in the experiment is typical of the whole Principality.

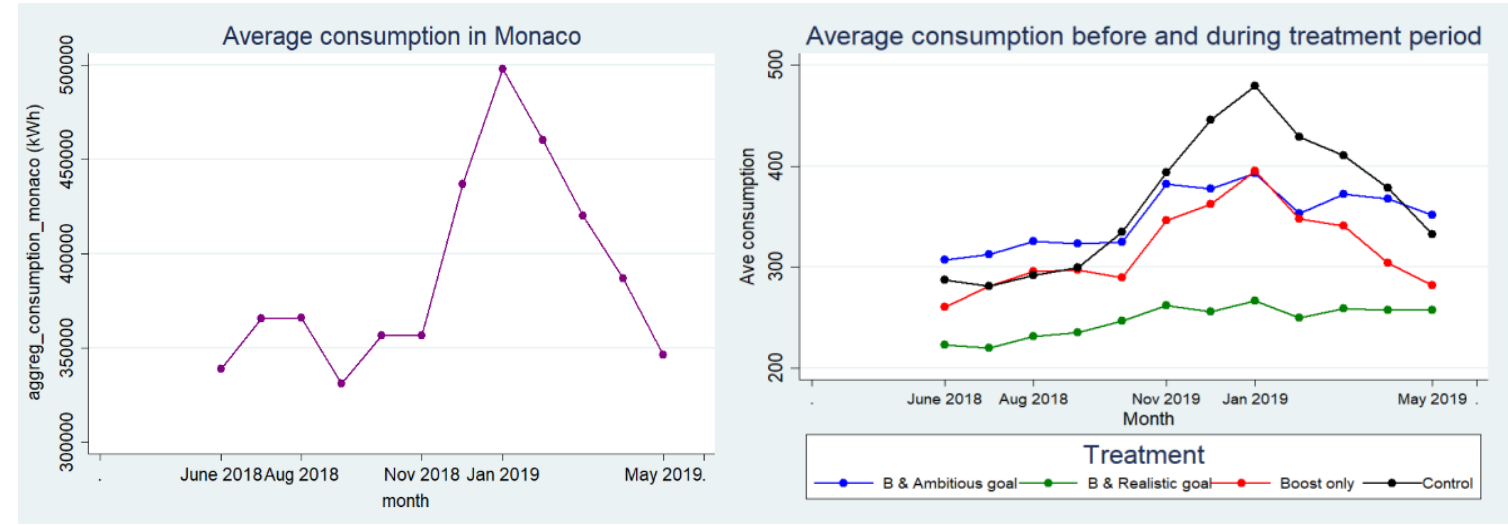




\section{Appendix 4-c. Panel monthly energy consumption}

\section{Average electricity consumption per group and per month}

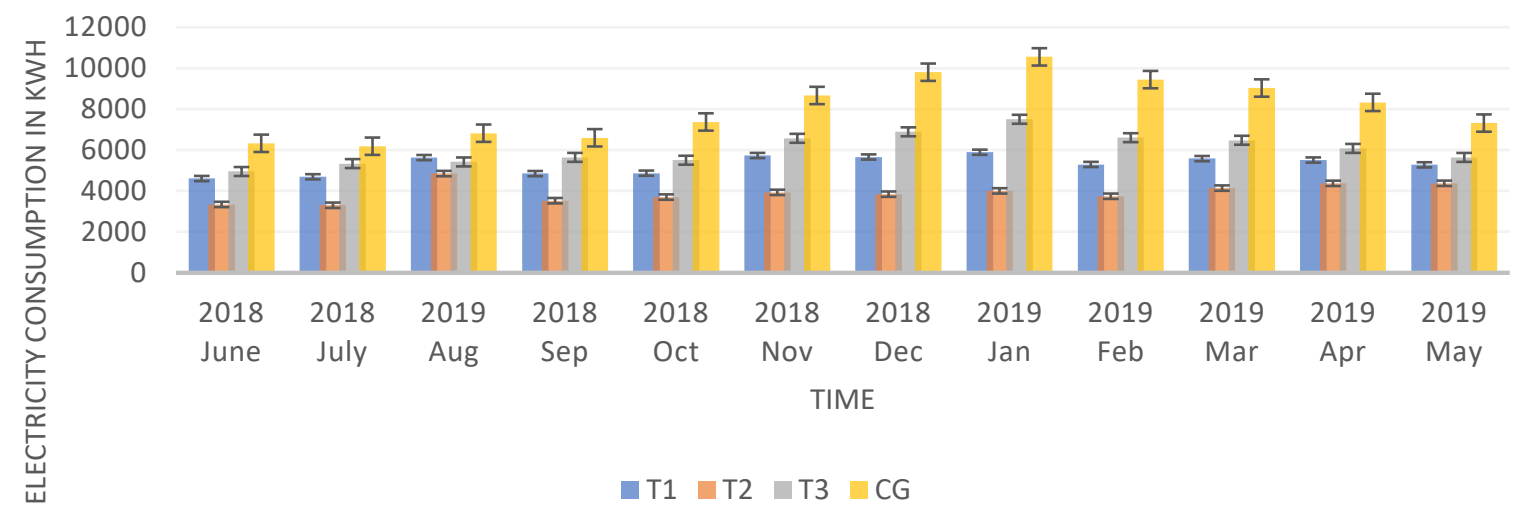

Appendix 5. GEB scale: energy conservation behaviors (Kaiser and Biel, 2000)

- I wait until I have a full load before doing my laundry (Q23-a)

- I do not use the prewash facility on my washing machine (Q23-b)

- The heating is turned off during the night (Q26)

- In winter, I turn up the heating, so I do not have to wear heavy clothes (Q26)

- In winter, I reduce the heating when I leave home for longer than 4 hours (Q26)

- I turn off lights in unoccupied rooms (Q28)

- I mainly use eco efficient light bulbs (Q27) 
Appendix 6. Model variables

\begin{tabular}{|c|c|}
\hline Variable names & Definition \\
\hline \multicolumn{2}{|l|}{ Dependent variable } \\
\hline Energy consumption & Each household's average monthly electricity consumption \\
\hline \multicolumn{2}{|l|}{ Independent variables } \\
\hline Boost \& high goal (T1) & $\begin{array}{l}1 \text { if the household received a high energy reduction goal coupled with boosts and } 0 \\
\text { otherwise }\end{array}$ \\
\hline Boost \& low goal (T2) & $\begin{array}{l}1 \text { if the household received a low energy reduction goal coupled with boosts and } 0 \\
\text { otherwise }\end{array}$ \\
\hline Boost only (T3) & 1 if the household received boosts and 0 otherwise \\
\hline High NEP & 1 if the NEP score is greater than median of NEP score of the panel and 0 otherwise \\
\hline Men & 1 for men and, 0 otherwise \\
\hline Monegasque & 1 if the respondent is a native Monegasque and 0 otherwise \\
\hline French & 1 if the respondent has French nationality and 0 otherwise \\
\hline Italian & 1 if the respondent has Italian nationality and 0 otherwise \\
\hline Owner & 1 if the respondent is the homeowner and 0 otherwise \\
\hline Single & 1 if the respondent is single and 0 otherwise \\
\hline Married & 1 if the respondent is married and 0 otherwise \\
\hline Post-secondary diploma & 1 if the respondent has completed 2 years of higher education and 0 otherwise \\
\hline Higher education & 1 if the respondent has completed 3 years of higher education and 0 otherwise \\
\hline Master's/Engineer & 1 if the respondent has an engineering or a master's degree and 0 otherwise \\
\hline Employee & 1 if the respondent is an employee and 0 otherwise \\
\hline Higher intellectual professions & 1 if the respondent is a professional and 0 otherwise \\
\hline Surface (Area) & Apartment size \\
\hline No. of household members & Number of members of the household during the period of the experiment \\
\hline Environmental commitment & 1 for membership of an environmental NGO and 0 otherwise. \\
\hline Individual heating system & 1 if the household has an individual heating system and 0 otherwise \\
\hline $\begin{array}{l}\text { Previous participation in an } \\
\text { experiment }\end{array}$ & $\begin{array}{l}1 \text { if the household has previously participated in an experiment related to energy } \\
\text { consumption }\end{array}$ \\
\hline Individual electric heating system & 1 if the household has an individual electrical heating system. \\
\hline
\end{tabular}


Appendix 7. Difference-in-differences estimation results by trimester

\begin{tabular}{|c|c|}
\hline VARIABLES & $\begin{array}{c}\text { Household average energy consumption per } \\
\text { trimester }\end{array}$ \\
\hline First trimester & -22.29 \\
\hline Second trimester & ref \\
\hline Third trimester & $84.46 * *$ \\
\hline Fourth trimester & 23.18 \\
\hline$B \&$ ambitious goal $(T 1)$ & -26.16 \\
\hline$B \&$ modest goal (T2) & -83.62 \\
\hline Boost only (T3) & -77.64 \\
\hline Control (T4) & ref \\
\hline First trimester $* T 1$ & 22.10 \\
\hline First trimester $* T 2$ & 28.17 \\
\hline First trimester $* T 3$ & 14.50 \\
\hline Second trimester & ref \\
\hline Third trimester $* T 1$ & $-81.12 *$ \\
\hline Third trimester $* T 2$ & $-90.09 * *$ \\
\hline Third trimester*T3 & -37.94 \\
\hline Fourth trimester $* T 1$ & -9.99 \\
\hline Fourth trimester $* T 2$ & -25.00 \\
\hline Fourth trimester $* T 3$ & $-34.01 *$ \\
\hline Age & 8.686 \\
\hline Higher intellectual profession & -53.69 \\
\hline Employee & 18.30 \\
\hline Retired & 5.781 \\
\hline Household size (No. in household) & 47.44 \\
\hline High NEP & -8.610 \\
\hline Surface area & 0.224 \\
\hline Individual electric heating system & $94.33 *$ \\
\hline Full washing machine & 7.205 \\
\hline Prewash & -9.533 \\
\hline Turn off heating at night & 0.737 \\
\hline Turn on heating to avoid heavy clothes & 16.13 \\
\hline Reducing the heating for 4 hours absence & -2.763 \\
\hline Turn off the lights in unoccupied rooms & -15.00 \\
\hline Being part of Env. association & -84.24 \\
\hline Using eco efficient light bulbs & -14.79 \\
\hline Weather temperature & $-0.122 * *$ \\
\hline Constant & $318.5^{*}$ \\
\hline Observations & 708 \\
\hline$R$-squared & 0.349 \\
\hline Robust standard errors in parentheses & \\
\hline$* * * p<0.01, * * p<0.05, * p<0.1$ & \\
\hline
\end{tabular}


time ( time $_{\text {post }}$ it $)$

B \& ambitious goal $\left(T 1_{i}\right)$

B \& modest goal $\left(T 2_{i}\right)$

$-69.53$

Boost only $\left(T 3_{i}\right)$

$-70.39$

Control $\left(C G_{i}\right)$

Ref

time*T1 (time $_{\text {post }}$ it $* T 1_{i t}$ )

$-56.10 *$

time*T2 time $\left._{\text {post }}{ }_{i t} * T 2_{i t}\right)$

$-71.63 * *$

time*T3 (time $\left._{\text {post }}{ }_{i t} * T 3_{i t}\right)$

$-43.22$

Individuals' characteristics

Age

Higher intellectual profession

$-53.69$

Employee

18.30

Retired

5.781

Household's size

High NEP

Being part of Env. association

Dwelling's characteristics

Surface (Area)

Individual electric heating system

Energy curtailment behaviors

Full washing machine

Prewash

Turn off heating at night

0.737

Turn on heating to avoid heavy clothes

16.13

Reducing the heating for 4 hours absence

Turn off the lights in unoccupied rooms

Weather temperature ${ }^{2}$

$-0.134 * * *$

Average consumption in Monaco

Constant

Observations

R-squared

Robust standard errors in parentheses

$* * * \mathrm{p}<0.01, * * \mathrm{p}<0.05, * \mathrm{p}<0.1$

Appendix 8.

Table 8 provides a robustness check. We re-ran the estimations presented in table 5 including average consumption in Monaco as a control. The following table shows that the results do not change, and the coefficients remain significant which confirms our main results. 
